\title{
LUTAS E ESPORTES DE COMBATE COMO ELEMENTOS FORMADORES NA EDUCAÇÃO BÁSICA
}

\author{
Fernando Ferreira da Silva ${ }^{1}$
}

\begin{abstract}
RESUMO
A atividade física é essencial para trabalhar a mente e o corpo. Sendo importante mencionar que o esporte, no universo escolar, deve ser direcionado à busca pelo desenvolvimento da independência pessoal e disciplinar. Dessa forma, o presente artigo buscou descrever as lutas e os esportes de combate como elementos formadores na educação básica a fim de fornecer dados para sua inserção nas aulas de educação física. Assim, foram consultados diversos materiais, como documentos oficiais, artigos, livros e pesquisas na área da educação sob o formato de monografias, dissertações e teses, para a composição do corpus deste estudo. Almeja-se, portanto, desmitificar a relação conflituosa entre as lutas e os esportes de combate no espaço escolar como fomentadoras de violência, tendo em vista que o ensino destas pode possibilitar uma maior independência pessoal e aprimorar a disciplina.
\end{abstract}

Palavras-chave: Lutas; Esportes de Combate; Educação Física.

\begin{abstract}
Physical activity is essential to work the mind and body. It is important to mention that sport, in the school universe, should be directed to the search for the development of personal and disciplinary independence. Thus, this article sought to describe combat struggles and sports as formator elements in basic education in order to provide data for its insertion in physical education classes. Thus, several materials were consulted, such as official documents, articles, books and research in the area of education under the form of monographs, dissertations and theses, for the composition of the corpus of this study. Therefore, it aims to demystify the conflicting relationship between fights and combat sports in the school space as promoters of violence.
\end{abstract}

Keywords: Fights; Combat Sports; Physical Education.

\section{RESUMEN}

La actividad física es esencial para trabajar la mente y el cuerpo. Es importante mencionar que el deporte, en el universo escolar, debe dirigirse a la búsqueda del desarrollo de la independencia personal y disciplinaria. Así, este artículo buscó describir las luchas de combate y el deporte como elementos formadores en la educación básica con el fin de proporcionar datos para su inserción en las clases de educación física. Así, se consultaron diversos materiales, como documentos oficiales, artículos, libros e investigaciones en el área de la educación bajo la forma de monografías, disertaciones y tesis, para la composición del corpus de este estudio. Por ello, se pretende desmitificar la conflictiva relación entre las peleas y los deportes de combate en el espacio escolar como promotores de la violencia, considerando que la enseñanza de estos puede permitir una mayor independencia personal y mejorar la disciplina.

Palabras clave: Peleas; Deportes de Combate; Educación Física.

\footnotetext{
${ }^{1}$ Mestrando em Ciências da Educação pela Universidad Interamericana - PY. Graduado no curso de licenciatura plena em educação física (técnico em desportos), pela Universidade Salgado de Oliveira - UNIVERSO em 2003, Pós-Graduado no curso de Pós-graduação Lato sensu em nível de Especialização em educação física escolar na área de ciências da saúde pela Faculdade da Região dos Lagos - FERLAGOS - 2005. E-mail: fernandocabofrio@gmail.com
} 


\section{INTRODUÇÃO}

O conceito de lutas pode ser definido como disputas em que o(s) oponente(s) deve(m) ser subjugado(s), com técnicas e estratégias de desequilíbrio, contusão, imobilização ou exclusão de um determinado espaço na combinação de ações de ataque e defesa. Caracterizam-se por uma regulamentação específica a fim de punir atitudes de violência e de deslealdade (BRASIL, 1997, p. 70).

Isso significa que são práticas reconhecidas para a Educação Básica, embora muitos professores não utilizem seus conteúdos nas aulas. Tal realidade é bastante diferente dos países orientais que fazem uso dos esportes de combate nas aulas de Educação Física (MOCARZEL, 2011).

Um dos fatores que pode corroborar para a ausência de atividades de lutas nas escolas brasileiras é a associação que se faz dos esportes de combate com a incitação à violência (VERTONGHEN, 2010), quando, na verdade, deveriam ter grande reconhecimento na Educação Física. O que se vê é uma ideia pautada no pré-conceito e não na real filosofia das lutas, que é justamente contrária a todo o tipo de violência.

Antes de tratar da filosofia das lutas e esportes de combate, faz-se necessário apresentar o conceito de filosofia. Segundo o Dicionário Online do Português (2020), este termo possui muitos significados: Razão da existência humana; conjunto das reflexões particulares que buscam entender a realidade, a partir da razão; Sabedoria; reunião das regras ou princípios básicos que norteiam a vida prática: filosofia de botequim; Reunião dos conhecimentos ou ideias de uma pessoa; reunião de toda ciência, do conhecimento ou do saber racional; Amor à sabedoria, conhecido somente pelas pessoas que têm consciência de sua própria ignorância.

Seguindo as definições acima, observa-se, dentre outras, o amor à sabedoria, que leva ao autoconhecimento e ao autodesenvolvimento, e visa também à transmissão de valores morais e éticos, bem como o respeito ao próximo. Pelos PCNs, entende-se que, particularmente no Brasil, as danças, os esportes, as lutas, os jogos e as ginásticas, das mais variadas origens étnicas, sociais e regionais, compõem um vasto patrimônio cultural que deve ser 


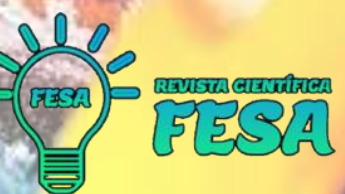

valorizado, conhecido e desfrutado. O acesso a esse conhecimento contribui para a adoção de uma postura não preconceituosa e não discriminatória diante das manifestações e expressões dos diferentes grupos étnicos e sociais (religiosos, econômicos e de diferentes origens regionais) e das pessoas que deles fazem parte.

\begin{abstract}
Na escola, a Educação Física pode fazer um trabalho de pesquisa e cultivo de brincadeiras, jogos, lutas (grifo nosso) e danças produzidos na cultura popular, que por diversas razões correm o risco de ser esquecidos ou marginalizados pela sociedade. Pesquisar informações sobre essas práticas na comunidade e incorporá-las ao cotidiano escolar, criando espaços de exercício, registro, divulgação e desenvolvimento dessas manifestações, possibilita ampliar o espectro de conhecimentos sobre a cultura corporal de movimento (BRASIL, 1997, p. 39).
\end{abstract}

Percebe-se, nos trechos acima, a preocupação tida com o preconceito, o esquecimento e a marginalização da cultura das lutas nas escolas, o que contraria toda a sua filosofia.

Segundo Kunz (2006), cabe ao professor trabalhar temas como preconceito, violência e saúde nas aulas de Educação Física através de discussões a fim de desmistificar a visão estereotipada das lutas. Torres (2010) aponta que não é dever da escola marcializar o aluno com as aulas sobre os esportes de combate, mas levá-lo ao conhecimento da cultura corporal de movimentos.

Lutar é uma ação social e cultural do homem, que existe desde os primórdios, com a finalidade de ataque e de defesa ao se sentir ameaçado por alguém (MOCARZEL, 2011). Há estudos que indicam que, no que se refere às lutas, quanto maior o tempo de prática menor a hostilidade (DANIELS; THORTON, 1990; 1992). A violência nas aulas de lutas, por sua vez, não faz parte dessa cultura e, por isso, contraria tal filosofia.

Portanto, as lutas possuem a filosofia dos esportes de combate orientais, em que se prega o respeito e o conhecimento das próprias limitações em relação ao próximo. Por este motivo, busca-se, com este artigo, descrever as lutas e os esportes de combate como elementos formadores na educação básica a fim de fornecer dados para sua inserção nas aulas de educação física. 


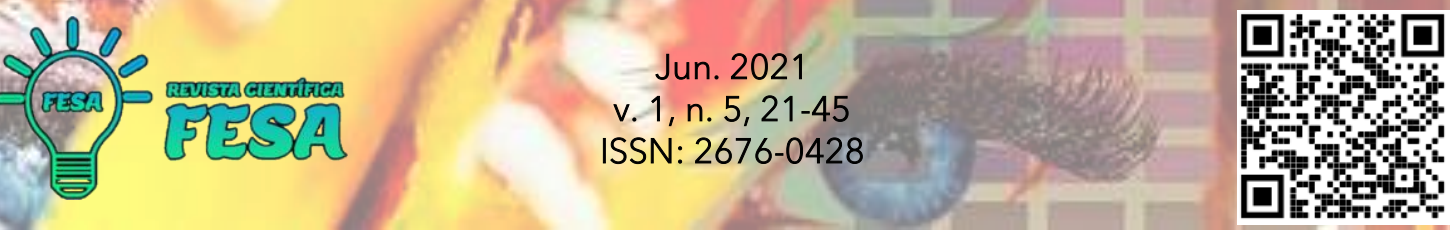

\section{TREINAMENTO}

Conforme mencionado anteriormente, as lutas são importantes por desenvolverem as capacidades físicas dos alunos, a sua relação consigo e com o próximo, além de propiciar a socialização, o respeito e a disciplina. Esses são alguns dos elementos considerados em sua filosofia.

No entanto, há muitas críticas na forma como as lutas são trabalhadas no ambiente escolar. Segundo os PCNs, por exemplo, por terem mais conhecimentos de natureza técnica, os professores de Educação Física confundem, constantemente, o "ambiente esportivo-competitivo com o escolareducacional". Acrescenta ainda que "o que predomina no Ensino Médio é a ideia de que a aula de Educação Física é um espaço para treinamento e aperfeiçoamento das habilidades desportivas" (BRASIL, 2000, p. 37).

Por isso, o que se vê, muitas vezes, é a preocupação do professor com campeonatos interescolares que priorizam treinamento com poucos alunos, "reduzindo a sua ação de educador à de treinador", em detrimento das aulas previstas no currículo, que insere todos os alunos (BRASIL, 2000, p. 37).

Segundo Breda (2010), os esportes têm um papel de manifestação sociocultural de múltiplos significados. Da mesma forma, pode-se entender as lutas, no ambiente escolar, que é uma prática que vai além do treinamento e segue objetivos educacionais.

De acordo com Lopes (2014), deve-se investir nas lutas no contexto escolar de modo dinâmico e não como treinamento de potencialidades físicas a fim de que não se reduza os esportes de combate a práticas individualistas, competitivas e até mesmo violentas. Assim sendo, entende a escola como um lugar para ensinar o aluno de forma significativa e prazerosa e não para treinálo.

Isso significa que as lutas e os esportes de combate não devem ser apenas praticados na escola, mas que seus conteúdos devam ser estudados para que os alunos entendam seus verdadeiros significados (KUNZ, et al, 2006, p. 57).

Nos PCNs do Ensino Fundamental também há uma preocupação com a forma como os jogos são praticados nas escolas. O documento aponta: 
[...] quando se diz popularmente que "jogo é jogo e treino é treino", o que se explicita é o alcance e a limitação que a própria técnica traz em si mesma. $O$ exercício de alguma prática da cultura corporal numa situação em que todas as variáveis pudessem ser controladas e previstas inviabilizaria a ligação entre a técnica e o uso intencional que o sujeito faz dessa mesma técnica, com o seu estilo pessoal, e da improvisação determinada pelo momento. No caso específico dos jogos e dos esportes, tornaria mecânica uma ação cuja riqueza reside na sua fascinante imponderabilidade (BRASIL, 1997, p. 49).

Pode-se trazer essa questão para o contexto dos esportes e também das lutas. A aprendizagem efetiva da prática das lutas não se dá quando se tenta automatizar, repetir e reproduzir os movimentos ou gestos estereotipados. É preciso que o aluno se aproprie do processo de construção de conhecimentos relativos ao corpo e ao movimento e construa uma possibilidade autônoma de utilização de seu potencial gestual (BRASIL, 1997, p. 27).

O objetivo do ensino de lutas deve ser para o treinamento do aluno à uma luta específica para fins de competição ou de alcance de movimentos técnicos ideais, pois seria essa uma visão tecnicista e apenas biologista (AGUIAR, 2008).

No modelo tradicional, o professor ensinava regras aos estudantes que eram obrigados a segui-las. Entretanto, novos estudos demonstraram a ineficácia dessa ação pedagógica e propuseram novas possibilidades de se pensar a Educação Física, de forma a contribuir para a formação de sujeitos capazes de interferir na realidade criticamente.

É importante entender as lutas enquanto componente curricular das aulas de Educação Física, presentes nos conteúdos estabelecidos pelos PCNs. Portanto, as lutas não ficarão restritas a atividades recreativas ou a prática de treinamento desportivo institucionalizada, como acontece com o judô e o caratê, por exemplo. Ademais, é necessário ainda proporcionar ao estudante 0 conhecimento das diferentes lutas e esportes de combate (LANÇA NOVA, 2006, p. 29).

\section{FORÇA}

Segundo os PCNs do Ensino Fundamental, historicamente, suas origens militares e médicas e seu atrelamento quase servil aos mecanismos de manutenção do status quo vigente na sociedade brasileira contribuíram para que tanto a prática como a reflexão teórica no campo da Educação Física 
restringissem os conceitos de corpo e movimento - fundamentos de seu trabalho - aos seus aspectos fisiológicos e técnicos (BRASIL, 1997, p. 28).

Entretanto, faz-se necessário estender esse conceito e entender a Educação Física através de uma visão mais ampla. O documento acrescenta que é necessário superar a ênfase na aptidão física para o rendimento padronizado, decorrente deste referencial conceitual, e caracterizar a Educação Física de forma mais abrangente, incluindo todas as dimensões do ser humano envolvidas em cada prática corporal (BRASIL, 1997, p. 28).

A esse conceito de aptidão física inclui-se um conjunto de elementos, tais como a força, a resistência e a velocidade, considerados indispensáveis à boa prática das atividades, enquanto, ao de rendimento padronizado, inclui-se o desempenho corporal que todos, igualmente, devem alcançar.

A crítica que se faz é com relação à importância dada à tal aptidão física (à força, por exemplo) em detrimento de questões culturais, sociais, políticas e afetivas dos indivíduos. Tradicionalmente, as avaliações feitas nas aulas se baseiam, inclusive, a testes de velocidade, força e resistência para medir se 0 aluno apresenta boa aptidão. Entretanto, não se compreende que esses fatores não são os mais relevantes, tendo em vista a necessidade de se entender que cada estudante tem suas limitações e motivações individuais.

O objetivo das lutas e dos esportes de combate não pode se limitar a testes de força, por exemplo. Segundo Lopes (2014),

[...] não se trata mais daquela avaliação padronizada que espera o mesmo resultado de todos. Isso significa dizer que, por exemplo, se um dos objetivos é que o aluno conheça alguns dos seus limites e possibilidades, a avaliação dos aspectos físicos estará relacionada a isso, de forma que o aluno possa compreender sua função imediata, o contexto a que ela se refere e, de posse dessa informação, traçar metas e melhorar o seu desempenho. Além disso, a aptidão física é um dos aspectos a serem considerados para que esse objetivo seja alcançado: o conhecimento de jogos, brincadeiras e outras atividades corporais, suas respectivas regras, estratégias e habilidades envolvidas, o grau de independência para cuidar de si mesmo ou para organizar brincadeiras, a forma de se relacionar com os colegas, entre outros, são aspectos que permitem uma avaliação abrangente do processo de ensino e aprendizagem (LOPES, 2014, p. 29).

Ter uma visão mais abrangente sobre a aptidão física, sobretudo à força física, é uma das possibilidades para a quebra, inclusive, de pensamentos estereotipados em relação aos jogos, aos esportes e às lutas, bem como à diferença entre as competências de meninos e meninas. Por questões 
socioculturais, os meninos sempre foram incentivados a esportes que demandassem mais força e velocidade, enquanto as meninas eram estimuladas a praticar atividades que exigissem coordenação e equilíbrio.

Segundo Lopes (2014), a educação física e as lutas, de forma mais específica, são vistas como uma apreciação de esportes e lutas nos aspectos técnicos, táticos e estéticos, objetivando o trabalho com o corpo e as regras práticas, desvalorizando as questões histórico-sociais (LOPES, 2014, p. 32).

Portanto, o trabalho com gênero nas aulas de Educação Física, em que se privilegiasse atividades que envolvessem ambos os gêneros seria um meio de desenvolver neles a tolerância, a não discriminação e o convívio com as diferenças (LOPES, 2014, p. 31).

Compreende-se, por fim, que, se no modelo de ensino tradicional, as aulas de Educação Física eram voltadas ao desenvolvimento da capacidade de força do aluno, ou mesmo com o intuito de mero treinamento técnico, como explicitado na seção anterior, novas concepções e propostas trazem uma outra forma de pensar o ensino.

Para tratar essa problemática, os PCNs fazem propostas e distinguem organismo e corpo, sendo o primeiro relacionado às características fisiológicas do ser humano e o segundo às questões socioculturais. Assim sendo, a Educação Física deve abordar em seus conteúdos a integração do aluno à cultura corporal de movimento e, ao mesmo tempo, formar o cidadão para produzi-la e transformá-la, "instrumentalizando-o para usufruir dos jogos, dos esportes, das danças, das lutas e das ginásticas em benefício do exercício crítico da cidadania e da melhoria da qualidade de vida" (BRASIL, 1997, p. 29).

\section{DISCIPLINA}

Conforme explanado nas seções anteriores, as lutas e os esportes de combate não se resumem apenas à aptidão física, a técnicas ou a treinamento. Elas ensinam aos seus praticantes valores, tais como o respeito a si mesmo e ao próximo, o autocontrole e, inclusive, a disciplina. Esta não pode ser confundida com aquela que pune, como muitos pensam ser.

Cabe, por isso, trazer algumas definições do termo. Segundo o Dicionário Online do Português, "disciplina" significa: Obediência aos preceitos, às regras; Modo de agir que demonstra constância, métodos; Respeito a um regulamento; 


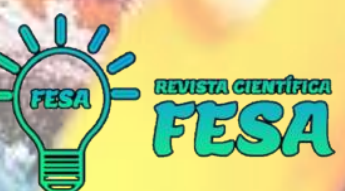

submissão ou respeito às regras, às normas, àqueles que são seus superiores etc; Matéria ensinada na escola, em faculdades; Boa conduta; Regulamentação que garante a satisfação de indivíduos ou instituições; Conjunto dos regulamentos destinados a manter a boa ordem em qualquer assembleia ou corporação; a boa ordem resultante da observância desses regulamentos.

Portanto, dizer que a luta tem como filosofia ensinar a disciplina implica que essa prática vai além do estímulo à força, ao treino, à velocidade e à resistência. Esses elementos são importantes, porém não mais do que os valores socioculturais, o respeito às regras, a boa conduta e a obediência aos preceitos.

A disciplina é um elemento enfatizado em muitos estudos sobre as lutas, tendo em vista seu valor cultural e social. Muitos autores, que se debruçam no tema da luta, se preocupam em mencioná-la.

Segundo Souza Junior e Santos (2010), como parte da cultura humana, as lutas representam um meio eficaz de educação e um conjunto de conteúdos altamente importante para a Educação Física escolar, pois, qualquer que seja a modalidade de luta, exige respeito às regras, a hierarquia e a disciplina, valorizando a preservação da saúde física e mental de seus praticantes. As lutas assim como os demais conteúdos da educação física, devem ser abordadas na escola de forma reflexiva, direcionada a propósitos mais abrangentes do que somente desenvolver capacidades e potencialidades físicas (SOUZA JUNIOR; SANTOS, 2010).

Para Preyer (2000, p. 71), além de desenvolver as capacidades físicas, as lutas auxiliam o aluno na sua relação consigo mesmo e com o grupo, ao propiciar elementos que visam à socialização, a competitividade, a disciplina e o respeito, característicos de sua tradição e filosofia (PREYER, 2000, p. 71).

Segundo Oliveira; Reis Filho (2013), as lutas podem ser inseridas no contexto escolar não somente como outra modalidade como as tradicionais (futsal, basquetebol, voleibol e handebol), mas também a partir de atividades que possuem elementos da luta, como por exemplo, as brincadeiras de cabo-deguerra, braço de ferro e outras. Sendo assim, o conteúdo lutas pode contribuir para o esporte competitivo e de alto rendimento, como, no caso da escola, colaborar na formação de um indivíduo cooperativo, disciplinado e que utilize os seus ensinamentos e fundamentos de forma positiva junto da sociedade em que 


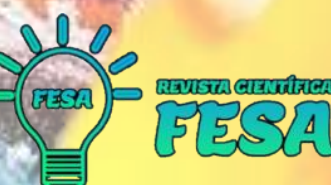

vive (OLIVEIRA; REIS FILHO, 2013).

Dessa forma, entende-se que não há incentivo à violência quando se pensa em trabalhar as lutas nas escolas, haja vista as inúmeras capacidades sociais, culturais e cognitivas, bem como muitos valores, que são desenvolvidos através dos esportes de combate. De acordo com Oliveira (2019):

\begin{abstract}
As lutas desenvolvem capacidades físicas importantes nos alunos, assim como as principais capacidades motoras essências para seu desenvolvimento saudável, como lateralidade, noção corporal, espacial e temporal, coordenação geral, flexibilidade e outros benefícios. Capacidades cognitivas também são desenvolvidas como raciocínio, atenção e percepção. Além do quesito social e afetivo que estimulam a socialização, trabalho em equipe e formação de opinião (OLIVEIRA, 2019).
\end{abstract}

Portanto, se forem estimuladas apropriadamente, com boa orientação do professor, nas aulas de Educação Física, as lutas somente irão favorecer 0 desenvolvimento integral dos alunos no que diz respeito à disciplina e, mais especificamente, à autodisciplina.

\title{
CAPOEIRA: DA LUTA À DANÇA
}

Os PCNs entendem que a Educação Física uma área que trata de um tipo de conhecimento, denominado cultura corporal de movimento, que tem como temas o jogo, a ginástica, o esporte, a dança, a capoeira e outras temáticas que apresentarem relações com os principais problemas dessa cultura corporal de movimento e o contexto histórico-social dos alunos (BRASIL, 1997, p. 26).

Observa-se, assim, que a capoeira está prevista no documento para o currículo escolar (PCNs), inserida no grupo de atividades rítmicas e expressivas, mais especificamente em danças populares, manifestações culturais e desenhos coreográficos: "vivência de danças folclóricas e regionais, compreendendo seus contextos de manifestação (carnaval, escola de samba e seus integrantes, frevo, capoeira, bumba-meu-boi etc.)" (BRASIL, 1997, p. 78).

A origem da capoeira se deu, segundo Silveira (2003, p. 35), "no Brasil Colônia", época "em que os negros escravos foram trazidos à força da África Ocidental a este país tropical". Eram eles "a principal mão de obra usada pelos fazendeiros na época.".

Para Mello (2002), as técnicas da capoeira visavam ao ataque e à defesa, 


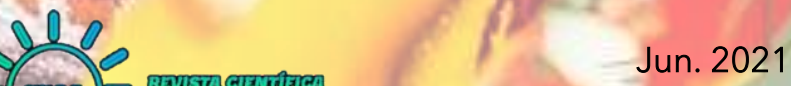

devido à necessidade de os escravos se autodefenderem e resistirem aos opressores, feitores e capitães do mato, em situação de fuga. Tais fugas ocorriam em lugares denominados capoeiras. Daí o surgimento desse termo.

Aos poucos a capoeira se propagou por todo o país no intuito de defesa pela liberdade, sendo transmitida oralmente de geração em geração. Medeiros (2016, p. 17) aponta que a capoeira tem 300 anos e que sua atuação se dá em mais de 150 países. "Ela já foi considerada marginal e quase desapareceu, porém continua sendo difundida porque é uma forma de resistência, é dança, é luta, é integração, é um modo de vida.". Acrescenta que:

\begin{abstract}
A partir daí reúne um conjunto de movimentos como agilidade, técnica, força e começa a ensaiar as rasteiras, os pulos, as cabeçadas que iriam se desenvolver e transformar - se em capoeira, uma dança mortal que sobrevive até os dias atuais. Hoje a Capoeira é conhecida como uma expressão cultural que integra cultura, disciplina, força e ritmo. É vista como um estilo de vida, um estado de espírito, e por isso, é praticada não só no Brasil, mas em vários países do mundo. Devido as suas características e a beleza dos movimentos e habilidades nos gestos é respeitada e, por meio sua prática, cidadãos nos diferentes países têm a oportunidade de aproximar-se dessa cultura afrobrasileira (MEDEIROS, 2016, p. 17).
\end{abstract}

Com relação à origem dessa manifestação cultural, a autora ressalta que a capoeira "nasceu da necessidade de liberdade de um povo, que a praticava disfarçada de dança, porque os donos dos escravos não aceitavam toda e qualquer forma de luta." (MEDEIROS, 2016, p. 17). Para atacar o opressor, era comum o uso de golpes para a autodefesa.

Acerca de seu conceito, se deve ser considerada uma luta ou uma dança, a autora aponta que o importante não é abrir uma discussão acerca da origem da capoeira, mas entender que é uma expressão cultural que se firmou no universo brasileiro como um instrumento de libertação contra a escravidão de um sistema dominante que tinha interesses pela colonização em busca de riquezas (MEDEIROS, 2016, p. 18).

Assim sendo, a capoeira é definida também como uma prática corporal e atividade de lazer inserida no cenário e no contexto da modernidade, que oferece uma conduta e proporciona ricas oportunidades de utilização, podendo ser vista como uma proposta cultural de prática esportiva social. Pode ser entendida como arte, dança, cultura, luta, arte marcial, jogo, esporte, música, folclore e filosofia, 
e pode ser encarada como um esporte que propicia uma elevada integração social (MEDEIROS, 2016, pp. 18-19).

Entende-se, portanto, que, no início, a capoeira surgiu como uma manifestação de luta, no intuito de defesa e ataque. No entanto, como "os senhores de engenhos proibiram então a prática dessa luta entre os escravos, (...) eles disfarçaram a capoeira colocando mímicas e danças acompanhadas de músicas." (MEDEIROS, 2016, p. 21). Assim, fundiram várias artes em uma só, mas principal é a luta. É jogo, é poesia, expressão corporal, filosofia de vida, mas acima de tudo, uma luta porque nasceu com os escravos como forma de resistir aos seus opressores (MEDEIROS, 2016, p. 22).

Para Medeiros (2016), a capoeira é verbalizada como dança na roda, pois os elementos fundamentais da dança estão presentes nessa luta, onde podemos observar os instrumentos, a música e o ritmo que é imposto de acordo com as canções entoadas durante a luta, a ginga, os movimentos dos pés e dos braços, portanto a conotação da dança se faz presente a todo o momento (MEDEIROS, 2016, p. 21).

Dessa forma, entende-se que, por fornecer ao indivíduo a possibilidade de um desenvolvimento físico, como força, equilíbrio, flexibilidade, ritmo, e também moral, espiritual e intelectual, a capoeira pode ser trabalhada no contexto escolar como uma forma também de inclusão social, resgatando a identidade e a história de um povo e buscando a superação da intolerância e das desigualdades. Fica clara a sua importância ainda para a "formação de caráter com a sociabilização, resgate a valores humanos e cultura nacional." (MEDEIROS, 2016, p. 31).

Ao lidar com o corpo, a mente e o espírito, a capoeira "melhora a autoestima das pessoas e colabora para inserção destas na sociedade." (MEDEIROS, 2016, p. 31). Logo, a autora advoga que deve ser trabalhada no ambiente escolar sem discriminações e preconceitos.

A autora cita o estudo de lório e Darido (2005), que também defendem a capoeira como uma manifestação cultural que deve ser ensinada nas escolas. Nas aulas de Educação Física, a capoeira pode ser trabalhada no intuito de "valorizar a nossa cultura, minimizar o preconceito, reconhecer e respeitar as diferenças étnicas, pautando-se na temática da pluralidade cultural." (IÓRIO; DARIDO 2005 apud MEDEIROS, 2016, p. 32). 
Portanto ela contribui para o desenvolvimento do educando de forma integral, realizando a fusão de corpo e mente. Pode ser um instrumento que junto às outras atividades transforma o espaço escolar em um espaço democrático e prazeroso para o educando e para os profissionais (MEDEIROS, 2016, p. 32).

Por fim, deve-se salientar que o ensino de capoeira nas escolas pode, então, promover a inclusão social ao aproximar as pessoas, abrindo espaços mais democráticos e possibilitando uma reflexão acerca da formação cidadã e dos direitos humanos, "pois na roda de capoeira participam homens, mulheres independentemente da origem, idade, cor, raça, credo, classe social ou grau de instrução. Ela (...) promove a inclusão social, uma melhor qualidade de vida e o direito a igualdade e cidadania." (MEDEIROS, 2016, p. 33).

\section{JUDÔ: DA LUTA AO ESPORTE OLÍMPICO}

Da mesma forma que a capoeira e o caratê, o judô é um exemplo de luta citado pelos PCNs (1997) e definido como uma prática mais complexa que as brincadeiras de cabo-de-guerra e braço-de-ferro. O documento o caracteriza ainda por conter "técnicas e estratégias de desequilíbrio, contusão, imobilização ou exclusão de um determinado espaço na combinação de ações de ataque e defesa" (BRASIL, 1997, p. 70), assim como as demais lutas.

O site Judô Ao Vivo, em uma matéria fornecida pela Federação Paulista de Judô sobre a origem desta luta, explica que havia um professor chamado Jigoro Kano que se dedicou a estudar técnicas de uma arte marcial japonesa, denominada "Jiu-jitsu", e resolveu torná-la um meio eficaz para o aprimoramento do físico, do intelecto e do caráter, num processo de aperfeiçoamento do ser humano, como uma das formas de arte marcial surgiu o Jiujitsu, luta corporal sem uso de armas, não tendo porém, registro preciso de sua origem (SITE JUDÔ AO VIVO, 2019. Acesso em 07 de dez. 2020).

Com o Jiu-jitsu", Kano percebeu que "suas técnicas poderiam ter valor educativo" e "passou a ter como meta transformar aquela tradicional arte marcial num esporte que pudesse trazer benefícios para o homem, ao invés de utilizá-la como arma de defesa pessoal simplesmente." (JUDÔ AO VIVO, 2019). 


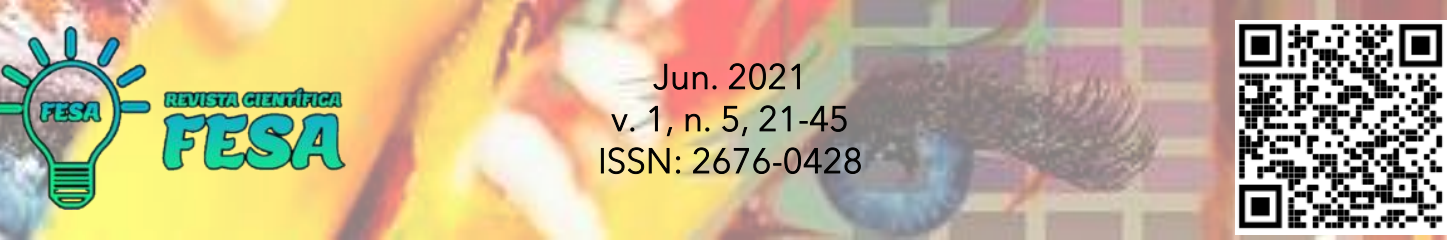

Sendo assim, o professor Kano analisou quais aspectos do Jiu-jitsu poderiam ser mudados para criar uma prática mais suave e defensiva, que trabalhasse o condicionamento físico, o espírito de luta e uma moral mais autêntica, e

[...] organizou-se de forma a constituir um sistema adequado aos métodos educacionais, como uma disciplina de educação Física, evitando as ações que pudessem ser lesivas ou prejudiciais à sua prática por qualquer leigo. Com esse intuito, Jigoro Kano em 1882 fundou sua própria escola e, para distinguir, de maneira evidente, das formas que identificavam o antigo Jiujitsu, denominou de JUDÔ KODOKAN, destinada à formação e preparação integral do homem através das atividades físicas de luta corporal e do aperfeiçoamento moral, sustentada pelos princípios e exaltação do caráter, que era a essência do espírito marcial dos samurais, o "Budo" (SITE JUDÔ AO VIVO, 2019. Acesso em 07 de dez. 2020).

O judô, assim, surgiu com técnicas e princípios filosóficos que garantem ao indivíduo autoconhecimento, autoconfiança e autocontrole do corpo em situações de alguma ameaça. Para Kano, "o Judô é uma arte para a autoproteção total." (JUDÔ AO VIVO, 2019). De acordo com o site,

[...] o rigor do treinamento que induz a humildade social, a perseverança, a tolerância, a cooperação, a generosidade, o respeito, a coragem, a compostura e a cortesia. (...) Quando falhas do conhecimento social e de moralidade constituem-se em problemas, um método de ensinar a cortesia entre as pessoas e melhorar a atitude social torna-se importante e, por isso, o Judô desempenha papel relevante nesse contexto, como forma de formar e lapidar os verdadeiros caracteres morais do ser humano (SITE JUDÔ AO VIVO, 2019. Acesso em 07 de dez. 2020).

Segundo o site do Centro de Treinamento de Judô (CTJ), Jigoro Kano fez parte do Comitê Olímpico Internacional e trabalhou ativamente no esporte, levando a ideia de que este deveria ser um meio de propiciar o respeito e o aprendizado entre as pessoas do mundo. No entanto, Kano não pensava em incluir o Judô como esporte olímpico, pois não queria que fosse visto como um simples jogo, longe de princípios, para ele, essenciais. "Eu o tomo como um princípio de vida, arte e ciência. (...) Judô deve ser tão livre de qualquer influência externa quanto a arte e ciência." (SITE CTJ, 2019).

Devido à Segunda Guerra Mundial, 
os jogos olímpicos de 1940 que seriam sediados no Japão foram cancelados. Em 1945, seguindo ordens dos Estados Unidos, o Ministro da Educação do Japão proibiu todo tipo de treinamento militar no país, incluindo centenas de artes marciais. As artes marciais foram eliminadas do curriculum de educação física das escolas e universidades (SITE CTJ, 2019. Acesso em 07 de dez. 2020).

De acordo com a Confederação Brasileira de Judô (CBJ), em 1964, o judô passou a integrar o programa olímpico em Tóquio, e, em 1969, foi fundada a Confederação Brasileira, obtendo a primeira medalha olímpica em 1972. Após 1984, começou a vencer em Jogos Olímpicos e ganhou medalhas todas as vezes, a ponto de ser considerado, em 2012, o esporte brasileiro que mais conquistou medalhas em Olimpíadas.

Assim, a CBJ passou a investir em sua estrutura e organização, bem como nas competições e nos atletas, atraindo, com isso, muitos patrocinadores. (SITE CTJ, 2019. Acesso em 07 de dez. 2020).

\section{JIU-JITSU: A MAIOR VÍTIMA DO PRECONCEITO}

O Jiu-Jitsu brasileiro, conhecido também como jujitsu ou jujútsu, é definido como uma arte marcial de raiz japonesa que se utiliza essencialmente de golpes de alavancas, torções e pressões para levar um oponente ao chão e dominá-lo. Literalmente, jū em japonês significa "suavidade", "brandura", e jutsu, "arte", "técnica". Daí seu sinônimo literal, "arte suave". Sua origem secular, como sucede com quase todas as artes marciais ancestrais, não pode ser apontada com precisão. Estilos de luta parecidos foram verificados em diversos povos, da Índia à China, nos séculos III e VIII. O que se sabe é que seu ambiente de desenvolvimento e refinamento foram as escolas de samurais, a casta guerreira do Japão feudal (SILVA; SILVA; ESPINDOLA, 2015, p. 187).

Acrescentam, ainda, que o surgimento dessa prática se deu pela necessidade de enfrentamento do oponente, com o uso de técnicas de defesa sem armas, tendo em vista que, em uma batalha, o samurai correria o risco de perder sua espada ou outros instrumentos.

Segundo Silva; Silva; Espíndola (2015), em 1917, um jovem chamado Carlos Gracie aprendeu a arte de se defender com Maeda, amigo de seu pai, após ter visto uma apresentação da luta em Belém. Em uma família de oito 


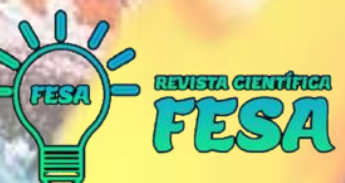

irmãos, Carlos Gracie se tornou uma referência e despertou o interesse por essa arte entre os demais de sua casa. Hélio Grace, seu irmão, também se tornou

[...] em suas aulas, ensinava a Carlos e a outros brasileiros - como Luiz França, que mais tarde seria mestre de Oswaldo Fadda - os conceitos de sua arte: em pé ou no chão, a força do oponente deveria ser a arma para a vitória; para se aproximar do adversário, o uso de chutes baixos e cotoveladas deveriam ser os artifícios antes de levá-lo para o chão. Para evolução nos treinos, lançava mão do randori, o treino à vera com um companheiro (SILVA; SILVA; ESPINDOLA, 2015, p. 188).

Os autores defendem que o Jiu-jitsu traz muitos benefícios à saúde do ser humano em qualquer fase de vida, porém a melhor idade para iniciantes é na sua infância. Quando criança, por exemplo, aos 6 anos de idade, "já começam a adquirir capacidade motora para participar de qualquer tipo de esporte que envolva organização." (SILVA; SILVA; ESPINDOLA, 2015, p. 188).

Advogam que a prática de corrida, saltos, empurrões e força favorece os movimentos corporais, mas também a área intelectual. (SILVA; SILVA; ESPINDOLA, 2015, p. 189). No entanto, é uma prática que gera ainda muito preconceito. Os autores Arruda; Souza (2014, p. 68) ressaltam que, no Brasil, o Jiu-Jitsu é visto "de forma bastante controversa, sintetizada em uma expansão que inverte seu sentido original pautado em sólidos valores morais e permite à diferentes atores sociais emitirem um julgamento negativo sobre ele.".

Acrescenta ainda que "alguns professores e também praticantes contribuem para este estado, acentuando uma visão distorcida sobre o Jiu-Jitsu, sobretudo por demonstrarem desconhecimento de sua origem e propagação como esporte.”. Quando "se pratica esta arte sem os critérios assumidos em sua origem (a prática pela prática), a filosofia real do Jiu-Jitsu é subvertida e se institui através de grupos ou sujeitos isolados, procedimentos reprováveis como a violência." (ARRUDA; SOUZA, 2014, p. 68).

Assim sendo, os professores precisam ir além do ensino técnico do Jiujitsu, com trabalho apenas no solo, para não instigarem a criação de estereótipos e levarem as pessoas a pensar que essa luta tem, por si só, o intuito de treinamento e de competição. Isso evitaria que seus praticantes fossem julgados pejorativamente.

Os autores mencionam que a desconstrução de estereótipos pode se dar através de uma metodologia diferente das aulas de Jiu-jitsu nas escolas. Citam 
Robbe (2006), que explica que o aprendizado do Jiu-Jitsu é um caminho longo que depende do desenvolvimento integral do praticante.

Assim, o aspecto físico vai sendo adaptado lentamente à luta; a emoção vai sendo harmonizada; a força vai sendo gradativamente dosada e usada com inteligência; a técnica vai sendo assimilada; a vontade vai sendo desenvolvida (ROBBE apud SILVA; SILVA; ESPINDOLA, 2015, p. 78).

Portanto, entendem que o respeito às particularidades de cada praticante pode levar ao conhecimento não somente de técnicas, mas à superação das próprias limitações. Para eles, esta superação está refletida na desconstrução de estereótipos e também na ruptura com as atuais metodologias que reduzem a competência do Jiu-Jitsu, colocando-o em uma posição de prática única e que por ocorrer no solo é vulgarmente conhecida como "agarra- agarra de machos" (SILVA; SILVA; ESPINDOLA, 2015, p. 78).

\section{CARATÊ: O PODER DA CONCENTRAÇÃO}

Os PCNs tratam da importância das lutas e de sua construção no contexto escolar. Propõe, assim, que deva haver "vivências de situações que envolvam perceber, relacionar e desenvolver as capacidades físicas e habilidades motoras presentes nas lutas praticadas na atualidade (capoeira, caratê, judô etc).". (BRASIL, 1997, p. 97).

Segundo Silva (2008, p. 2), o caratê teve sua origem no Japão, na llha de Okinawa, no arquipélago de Ryukyu. Nessa ilha, que pertencia a China, as pessoas não poderiam usar nenhum tipo de arma, portanto, a fim de se defenderem, tinham que utilizar secretamente as artes marciais chinesas, tal como o kung fu.

Posteriormente, essas artes marciais se expandiram e surgiu o caratê com uma filosofia baseada na manutenção de uma "vida saudável", com "disciplina, equilíbrio, através de dedicação, lealdade, autoconfiança do indivíduo.". Assim, se espalhou pelo mundo "não mais por arte marcial, agora como uma disciplina que trabalha o físico e o intelecto de seus praticantes." (SILVA, 2008, p. 3).

O lema é "Esforçar-se para a formação do caráter, fidelidade para com o verdadeiro caminho da razão, criar intuito de esforço, respeito acima de tudo e 


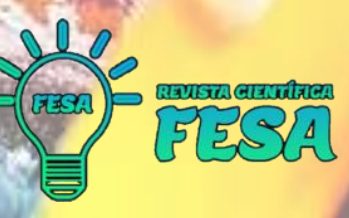

conter o espírito de agressão." (SASAKI, 1978 apud SILVA, 2008, p. 2). Silva (2008, p. 3) cita o fundador do caratê moderno Funakoshi e diz que, para ele:

O mais importante acontecimento do karatê moderno foi quando ele se transformou de arte marcial em esporte através das adaptações que sofreu, possibilitando aos seus praticantes saúde e bem-estar, pois com isso ele pretendia com seu método de luta, que visava à educação física como forma de defesa pessoal, e posteriormente como meio de vida e estando diretamente aliada à filosofia dos samurais e com base científica formar os estudantes de primeiro e segundo graus, em homens de caráter e espírito forte ajudando na sua formação como cidadãos (SASAKI, 1978 apud SILVA, 2008, p. 3).

Para seu fundador, o Caratê deveria estar no ambiente escolar, tendo em vista que tem muito a auxiliar as crianças. O Caratê tem como características "proporcionar para o ser humano qualidades como coordenação, motivação, autocontrole, concentração, atividade anaeróbica e aeróbica". Além disso, "tem uma filosofia voltada para o bem, um código de honra em que se baseia a razão, caráter, esforço, evitar a violência e manter o respeito." (SILVA, 2008, p. 4).

Segundo Maranzana (2008) citado por Silva (2008, p. 4), o Caratê trabalha:

[...]a auto-estima, o autocontrole, a autoconfiança, atenção, concentração, socialização e cidadania, (...) tem promovido resultados verdadeiramente satisfatórios, pois esses subsídios são de suma importância para a construção de um alicerce forte, de uma base sólida que evitarão que o indivíduo se desvirtue facilmente e farão com que este esteja inserido no contexto social de maneira digna de respeito e com preparação para a vida cotidiana (MARANZANA, 2008).

Lago e Campos (2019) demonstram, em seus estudos, a importância do Caratê não somente para os movimentos, mas para o desenvolvimento da psicomotricidade e, também, da concentração das crianças. Para os autores:

É frequente a reclamação dos professores das escolas quanto à falta
de concentração dos alunos nas aulas, que acaba prejudicando-os e
atrapalhando-os no desempenho escolar. Estudos ligados à psicologia
e à pedagogia comprovam que o Caratê tem grande influência para
ajudar no desenvolvimento dessas crianças que sentem dificuldade
para se concentrar nas suas atividades diárias. É importante destacar
que as lutas devem fazer parte da vida das crianças e também nas
aulas de educação física em escolas. Sabemos que o Caratê
proporciona para o ser humano qualidades como coordenação,
motivação, autocontrole, concentração, atividade anaeróbica e
aeróbica, durante as quais o aluno aprenderá alguns códigos de honra
baseados na razão, no caráter, no esforço, evitando a violência e
mantendo o respeito ao próximo (LAGO; CAMPOS, 2019, p. 6). 
Lago e Campos (2019) observaram em seu estudo de caso que as crianças, principalmente entre 5 e 12 anos de idade, independente do gênero, conquistaram melhor coordenação e concentração após as aulas de Caratê.

Portanto, concluíram que os exercícios que são aplicados no Caratê têm o objetivo de desenvolver as capacidades motoras, de forma lúdica. Busca-se adaptar as aulas aos diferentes níveis de habilidades dos alunos, respeitando o processo de amadurecimento deles, observando a individualidade biológica de cada um (LAGO; CAMPOS, 2019, p. 14).

\title{
TAE KWON DO: O USO DO TEMPO E DA HABILIDADE
}

Em Martins, Freitas e Bueno (2016), os autores apontam o período em que surgiu a prática do Tae Kwon do:

\begin{abstract}
[...] por volta de 1945, com o fim da segunda guerra mundial e a rendição do Japão aos Estados Unidos, a Coréia se via livre pela primeira vez de um regime de colonização que perdurou por 35 anos. Concedendo espaço para o militar Choi Hong Hi conseguir finalmente realizar seu sonho de aprimorar as artes marciais coreanas e uni-las em uma única arte, a que denominou de taekwondo. (AKILIAN, 2009; COOK, 2011; COSTA, ANTUNES, 2015; CRISTINA et al, 2015 apud MARTINS; FREITAS; BUENO, 2016, p. 12).
\end{abstract}

Acrescentam ainda que, em 2000, se tornou um esporte olímpico e, com isso, teve não apenas suas técnicas aprimoradas, mas o conhecimento do desenvolvimento biológico "para um bom desempenho do indivíduo, tanto de forma física como técnica." (MARTINS; FREITAS; BUENO, 2016, p. 12).

Ao citarem o trabalho de Arruda e Silva (2009), demonstram que o indivíduo tem suas próprias capacidades motoras e, portanto, sua evolução está associada ao contexto em que vive, "pois uma vez dentro de um meio social passa a moldar-se a ele, não somente de forma física, mas também sociocultural." (ARRUDA; SILVA, 2009 apud MARTINS; FREITAS; BUENO, 2016, p. 12).

Nos primórdios, o homem precisava se proteger dos seus inimigos para conseguirem sobreviver. Então, "passaram a utilizar seus pés e mãos como forma de defesa (...). Séculos mais tarde, através de seu desenvolvimento, esta 
proteção passou a ter um formato sistêmico, com padrões de movimento e simulações de luta." (MARTINS; FREITAS; BUENO, 2016, p. 12).

De acordo com os autores, o termo Tae kwon do significa "caminho dos pés e das mãos", tendo em vista que se usa o corpo todo, especialmente os punhos e os pés, em tal prática. Assim sendo, se desenvolveu enquanto esporte e cultura. Para eles:

[...] a filosofia do taekwondo manteve-se integra, o equilíbrio entre corpo, mente e espírito, através da prática constante e da dedicação à arte para que, com o tempo, o praticante possa ser um cidadão honrado e equilibrado. Foi neste caminho que se vislumbrou o esporte como algo mais abrangente, a formação de um mundo mais integro e moral, por meio de um profissional que não trabalhe somente a preparação física e a técnica, mas também vise a filosofia da arte, sua cultura e o próprio ser humano como um todo (AKILIAN, 2009 apud MARTINS; FREITAS; BUENO, 2016, pp. 15-16).

Dentre as inúmeras técnicas do Tae kwon do, a saber: autoconhecimento, equilíbrio e precisão, estão também o correto uso do tempo e da habilidade. Destaca-se, por exemplo, a habilidade de leitura do oponente que tem a ver com a previsão das ações do adversário no sentido de prever golpes e atos de defesa. Como diz o coach de Tae kwon do, Guilherme Maciel, no artigo "As 3 habilidades para lutar taekwondo" (2016), "é como se pudesse ler a mente do oponente e nesse jogo ganha quem consegue ler melhor.".

Assim sendo, o uso adequado do tempo se faz extremamente necessário, na medida em que para ler o oponente, deve-se prever sua ação antes mesmo de ele começar a fazê-la. Conforme Peter Drucker, citado por Maciel (2016), "O que não pode ser medido, não pode ser melhorado". Portanto, a estratégia correta aliada ao uso preciso do tempo torna o praticante um ótimo leitor da luta.

\begin{abstract}
A leitura da luta consiste em prever ações do adversário e tomar ações melhores que ele, para isso é necessário estar atento ao que melhor se adapta no momento. Você já deve ter presenciado lutas em que o favorito perde e não consegue impor seu jogo, não é mesmo?! Isso acontece pelo fato de que seu oponente usou a estratégia correta, lendo a luta de uma forma melhor (...) (MACIEL, 2016, s/p).
\end{abstract}

Cabe ressaltar que o tempo é relevante nessa prática, então, nessas notas, deve-se colocar o tempo dos chutes: "a média de chutes máximo por minuto, chutes médios por round, chutes máximos com cada perna..." (MACIEL, 2016). 
Cada atleta segue um padrão de luta, alguns chutam melhor com a perna da frente, outros com a de trás, outros preferem giros, entre outras situações... Seu trabalho consiste em mentalmente fazer anotações sobre o padrão desse atleta e você tem em torno de meio round para fazer (...). Treine com situações hipotéticas, como por exemplo: seu colega de treino decide atacar mais com a perna da frente (sem te falar previamente) e você tem 45 segundos para identificar o padrão, repita o exercício alterando o padrão e tente identificar novamente. Esse simples hábito irá te tornar um excelente leitor de lutas e seus resultados irão melhorar significativamente (MACIEL, 2016, s/p).

Para isso, algumas dicas são dadas aos seus praticantes, como permitir o oponente se movimentar primeiro; se atentar à forma como ele ataca e se defende; e a tomar anotações sobre os treinos, a sua preparação física e a de seus adversários

\section{KUNG FU: A ESTRATÉGIA COMO ALIADA}

Ao longo das gerações, o Kung Fu se tornou uma prática de autodefesa que foi se transformando e adquirindo novos movimentos de combate ensinados, inclusive, na atualidade.

Henning (2001) citado por Ferreira; Souza; Junior (2017, p. 20) aponta que, com o passar dos tempos, o Kung Fu foi denominado "de diferentes formas ao longo da história da civilização chinesa, a partir da imposição de inúmeros significados estritamente afinados com as transformações operadas no âmbito desta sociedade na esteira de longo alcance.". Os autores citam ainda a definição de Reid e Croucher (2003, p. 266), como sendo "a prática diligente e o domínio perfeito de uma arte.".

O trabalho de Ferreira; Souza; Junior (2017, p. 20) menciona Cheng (2008) quando explica que o Kung Fu se desenvolveu com o Taoísmo, sendo "toda prática que fosse ao mesmo tempo física e espiritual, designando, portanto, tempo e energia dedicados à determinada atividade almejando-se, em última instância, certo nível de desenvolvimento e excelência.".

Segundo Apolloni (2004), foi somente no século XVIII que o Kung Fu chegou ao oriente "transportado por padres jesuítas que desenvolviam suas atividades na China, tendo esta arte se disseminado no Brasil a partir de fins da década de 1950 (FREITAS, 2004; FERREIRA, 2013).".

O Templo Shaolin, localizado no condado de Dengfeng, foi uma das 


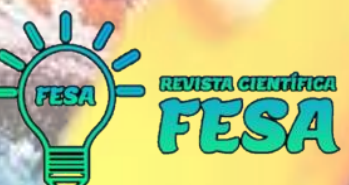

escolas de Kung Fu que trouxe dados sobre a origem das artes márcias da China. Para Ferreira; Souza; Junior (2017, p. 21), a "longevidade histórica e sua relação com práticas religiosas (...) trazem dados elucidativos para entender as transformações ocorridas no Kung Fu ao longo de sua história milenar construída no interior da sociedade chinesa.". Acrescentam também que:

\begin{abstract}
Embora possa parecer que Shaolin foi o berço do Kung Fu, entendemos como sendo no mínimo arriscado atribuir a apenas uma localidade ou pessoa isolada a gênese de toda uma prática e conceito marcial. Preferimos assim, em conformidade então com o que é sugerido na perspectiva configuracional e processual de Norbert Elias (1994a,1994b), desconsiderar um marco zero para circunscrever a gênese dessa prática de modo a nos atentarmos para uma série de processos, transições e rupturas que o Kung Fu enfrentou dentro e no entorno do Templo (FERREIRA; SOUZA; JUNIOR, 2017, p. 21).
\end{abstract}

Foi no extremo oriente que as artes marciais formaram um conjunto de técnicas com base no conceito chinês do Tao, que significa "caminho". De acordo com o tópico "Kung Fu - Estratégias de combate", publicado no site TibiaBR (2005), "o taoísmo é a base de sustentação que rege todo o pensamento chinês.". Portanto, seu praticante deve seguir o Tao para se prevenir de agressões e acidentes.

Para isso, as estratégias de combate no Kung Fu usam a teoria de Yin/Yang, que prega o uso da força do oponente contra ele próprio, a gentileza e a moderação. Assim, recomenda-se que:

[...] quando o adversário for duro, seja macio. Quando o adversário for macio, seja duro. Quando o adversário agarrar, golpeie. Quando o adversário golpear, agarre-o. Quando for atacado não se oponha ao ataque, complemente e o absorva sua força (SITE TIBIABR, 2005. Acesso em 10 de dez. 2020).

Pela teoria de Yin/Yang no Kung Fu, entende-se que a estratégia deve ser usada como aliada por seus praticantes. Uma delas é o conhecimento do momento em que se deve ceder, mas não completamente. Tal atitude se baseia na Lei da harmonia e no entendimento da autopreservação no Kung Fu, que compreende que o lutador está em harmonia com a força do adversário e não contra ela. Ademais, deve-se se preservar, seguindo os movimentos de seu oponente sem oposição e disputa. 
Segue, nessa linha, o conceito do Wu Wei que prevê a não-reação, o que não quer dizer passividade, mas uma resposta ao ataque sem obsessão para alcançar a vitória. A perda do oponente é vista, nesse viés, com um sentido de vitória. Acrescenta-se ainda que "quando um homem Kung $\mathrm{Fu}$ finalmente compreendeu a teoria do Yin/Yang, ele já não jogará com a chamada gentileza ou firmeza. Ele simplesmente faz, atua de acordo com os requerimentos do momento".

Portanto, é preciso entender que, assim como nas demais lutas vistas aqui, o conhecimento de estratégia é essencial no Kung Fu, se tornando um forte aliado para vencer o oponente. Cabe dizer que não basta ensinar a técnica das lutas por si só, mas estratégias metodológicas que respeitem o corpo humano e que sejam úteis à sua vida (BRASIL, 1997).

\section{CONSIDERAÇÕES FINAIS}

Compreende-se que, nas aulas de Educação Física, o intuito não é tornar o aluno um lutador ou um praticante profissional de artes marciais, mas um cidadão capaz de utilizar os conhecimentos dos conteúdos adquiridos com cada luta, a saber: capoeira, karatê, jiu jitsu, kung fu, dentre outras discutidas neste estudo, que contêm valores e conceitos bastante ricos.

Os Parâmetros Curriculares Nacionais (PCNs) (BRASIL, 1997) recomendam que os esportes de combate sejam abordados como cultura humana de forma lúdica e que seja ainda ministrada pelo professor de Educação Física para que não escape a essência dessa prática sob o aspecto educacional. Isso se deve ao respeito que deve ser dado ao ser humano no que se refere ao desenvolvimento de suas características físicas, mas, também, motoras, cognitivas, culturais, afetivas e sociais (FERREIRA, 2006).

Dessa forma, espera-se que o trabalho com lutas e esportes de combate surjam de modo natural durante as aulas de educação física a fim se somar com as demais habilidades desenvolvidas na referida disciplina. 


\section{REFERÊNCIAS BIBLIOGRÁFICAS}

AGUIAR, C. A Legitimidade das Lutas: conteúdo e conhecimentos da Educação Física escolar. 2008. Trabalho de conclusão de curso (Graduação) Curso de Educação Física, Universidade Estadual de Campinas, Campinas, 2008.

APOLLONI, R. W. Shaolin à brasileira: estudo sobre a presença e a transformação de elementos religiosos orientais no Kung-Fu praticado no Brasil. Dissertação de Mestrado, PUC- São Paulo, 2004.

ARRUDA, P. D. P.; SOUZA, B. J. DE. Jiu-Jitsu: uma abordagem metodológica relacionada à quebra de estereótipos. Redfoco. Natal. Vol. 1, n.1, 2014. pp. 67-89.

BRASIL. Parâmetros Curriculares Nacionais (PCNs): Educação Física. Brasília: MEC, 1997.

BRASIL. Parâmetros Curriculares Nacionais (PCNs): Linguagens, Códigos e suas tecnologias. Brasília: MEC, 2000.

BREDA, M.; GALATTI, L.; SCAGLIA, A. J.; PAES, R. R. Pedagogia do esporte aplicada às lutas. São Paulo: Phorte, 2010.

DANIELS, K., THORNTON, E. An analysis of the relationship between hostility and training in the martial arts. Journal of Sports Sciences 8, 95-101, 1990.

DANIELS, K., THORNTON, E. Length of training, hostility and the martial arts: a comparison with other sporting groups. British Journal of Sports Medicine 26, 118-120, 1992.

FERREIRA, F. D. C.; SOUZA, J. de; JÚNIOR, W, M. O processo de difusão do Kung Fu no ocidente: entre o sentido de perda e a inevitabilidade da perda do sentido. Motrivivência, Florianópolis/SC, v. 29, n. 51, p. 13-27, julho/2017.

HENNING, S. E. What's in a name? The etymology of Chinese Boxing. Journal of Asian Martial Arts, vol.10, n.4, 2001.

IÓRIO, L. S.; DARIDO, S. C. Capoeira. In: DARIDO, S. C.; RANGEL, A. I. C. (Org.). Educação Física na Escola: implicações para a prática pedagógica. Rio de Janeiro: Guanabara Koogan, 2005. p. 262-287. 
JUDÔ CTJ. O judô como esporte olímpico. 2019. Disponível em: https://www.judoctj.com.br/o-judo-como-esporte-olimpico/ Acesso em 07 de dez. de 2020.

LANÇA NOVA, J. E. S. Lutas na Educação Física Escolar: alternativas pedagógicas. 70 f. Monografia (Licenciatura em Educação Física) - Universidade da Região da Campanha, Alegrete, 2006.

LOPES, M. L. As lutas na educação física: uma análise dos PCNS para o ensino fundamental. Corumbá - MS, 2014.

KUNZ, E. Transformação didático-pedagógica do esporte. 7. ed. ljuí: Unijuí, 2006.

KUNZ, E., et al. Didática da educação física 1/Org. ElenorKunz. - 4. ed. - ljuí: Ed. Unijuí - 160 p.: il. - (Coleção Educação Física). 2006.

LAGO, N. L. S.; CAMPOS, H. J. C. de. Influência do karatê-do no desenvolvimento psicomotor e concentração das crianças de 5 a 12 anos: Estudo de Caso. Universidade Católica do Salvador | Anais da 22a Semana de Mobilização Científica- SEMOC | 2019.

LOPES, M. L. As lutas na educação física: uma análise dos PCNS para o ensino fundamental. Corumbá - MS, 2014.

MACIEL, G. 3 habilidades para se destacar na luta de Taekwondo. 2016. Disponível em: https://blog.guilhermemaciel.com.br/3-habilidades-luta-detaekwondo/ Acesso em 09 de dez. de 2020.

MARANZANA, M. O karatê $\mathbf{e}$ as demais artes marciais atuais tem suas raízes mais remotas no século V. Disponível em: <http://www.geogities.com/michelmaranzana/origem.html. Acesso em: 09 de dez. de 2020.

MARCONI, M. A.; LAKATOS, E.M. Fundamentos da metodologia científica. 5 ed. SP: Atlas, 2003.

MARTINS, J. V. DE O.; FREITAS, R. M. M. P.; BUENO, C. A. M. O conhecimento da Educação Física para o ensino do Taekwondo na segunda infância. Rev. Cient. de Ciências Apl. da FAIP - ISSN: 2525-8028, v. 3, n. 6, nov. 2016. pp. 1132.

MEDEIROS, M P. Da S. Capoeira: da Marginalização à Reafirmação Identitária. Trabalho de conclusão de curso à Universidade Federal do Rio Grande do Norte. Currais Novos. 2016. 


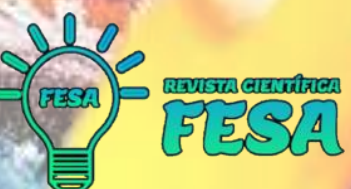

MELLO, A. da S. A história da capoeira: pressuposto para uma abordagem na perspectiva da cultura corporal. Centro Universitário Vila Velha. UVV. 2002.

MOCARZEL, R. C. da S. Artes marciais e jovens: violência ou valores educacionais? Um estudo de caso de um estilo de Kung-fu / Rafael Carvalho da Silva Mocarzel. - Niterói, 108p. 2011.

OLIVEIRA, C. A importância das lutas na educação física escolar para formação integral dos alunos. Revista Científica Multidisciplinar Núcleo do Conhecimento. Ano 04, Ed. 07, Vol. 06, pp. 37-47. Julho de 2019. ISSN: 24480959

OLIVEIRA, S. B.; REIS FILHO, A. Ensino de lutas na escola: elemento pedagógico ou estímulo à violência. Lecturas: Educación Física y Deportes, Revista Digital, Buenos Aires, v. 18, n. 180, 2013.

PREYER, C. T. Educação física escolar: a importância da diversificação no ensino de seus conteúdos. Campinas, 2000.

SASAKI, Y. Manual de Educação Física: karatê-do e Tênis. São Paulo: E.P.U., 1978.

SILVA, T. E. L. DA; SILVA, G. G. DA; ESPINDOLA, W. C. F. Os Benefícios do Jiu-Jitsu para a Saúde: um incentivo para a prática esportiva. Revista Científica da FASETE. 2015. pp. 186- 192.

SILVEIRA, J. A Educação Física escolar nas escolas públicas e os seus conteúdos: uma análise sobre a postura dos educadores acerca de seu campo de trabalho. IV EnFEFE Encontro Fluminense de Educação Física Escolar. Centro Esportivo Virtual: cev.org.br. 2003.

SOUZA JÚNIOR, T. P.; SANTOS, S. L. C. Jogos de oposição: nova metodologia de ensino dos esportes de combate. EFDeportes.com, Revista Digital. Buenos Aires, v. 14, n. 141, fevereiro 2010.

TORRES, L. R. Propostas pedagógicas para o ensino de lutas em escolas: uma visão sobre o universo do Kung Fu. Revista digital. Buenos Aires, ano 15, ํo147, 2010.

VERTONGHEN, J. The social-psychological outcomes of martial arts practice among youth: A review. Journal of Sports Science and Medicine. n.9, p.528$537,2010$. 